\title{
Differences in Sensitivity to a Triazole Fungicide Among Stagonosporopsis Species Causing Gummy Stem Blight of Cucurbits
}

Hao-Xi Li, Department of Plant Pathology, University of Georgia, Athens, GA 30602; Katherine L. Stevenson, Department of Plant Pathology, University of Georgia, Tifton, GA 31793; and Marin T. Brewer, Department of Plant Pathology, University of Georgia, Athens, GA 30602

\begin{abstract}
Li, H.-X., Stevenson, K. L., and Brewer, M. T. 2016. Differences in sensitivity to a triazole fungicide among Stagonosporopsis species causing gummy stem blight of cucurbits. Plant Dis. 100:2106-2112.

Gummy stem blight (GSB) is a destructive disease of cucurbits caused by three closely related Stagonosporopsis species. In the southeastern United States, GSB management relies heavily on triazole fungicides. Our objectives were to determine if resistance to triazoles has developed in populations of GSB fungi in the southeastern United States, and if so, to investigate the molecular basis of resistance. A tebuconazole sensitivity assay was conducted on 303 Stagonosporopsis citrulli and 19 S. caricae isolates collected from the southeastern United States in 2013 and 2014, as well as three $S$. citrulli, three $S$. cucurbitacearum, and six $S$. caricae isolates from other regions or years. Tebuconazole resistance was detected for all

19 S. caricae isolates from the southeastern United States and one $S$. caricae isolate from Brazil. All S. citrulli and S. cucurbitacearum isolates were sensitive to tebuconazole. For resistant and sensitive isolates of $S$. caricae, coding and promoter regions of the target gene $C y p 51$ were sequenced and expression levels of Cyp51 and ScAtrG (an ATP-binding cassette transporter) were measured. Tebuconazole resistance was not associated with mutations within Cyp51, multiple copies of Cyp51, changes in the promoter region, or increased expression of Cyp51 or ScAtrG. Tebuconazole resistance may explain the increase in frequency of $S$. caricae isolates recovered from GSB-infected cucurbits in Georgia.
\end{abstract}

Cucurbits are susceptible to gummy stem blight (GSB), a destructive foliar disease that has caused severe epidemics in the southeastern United States over the past several decades (Gusmini et al. 2005; Keinath et al. 1995; Schenck 1968; St. Amand and Wehner 1995). These epidemics can have major economic impacts, because more than one third of the cucurbits produced in the United States are from southeastern states, including Georgia, Florida, and South Carolina, which, alone, contribute approximately $\$ 356$ million to the local economy (NASS 2015). GSB not only decreases yield but, also, reduces fruit quality (Keinath 2000). GSB is caused by three morphologically similar but genetically distinct Stagonosporopsis species, S. cucurbitacearum (syn. Didymella bryoniae), S. citrulli, and $S$. caricae (Stewart et al. 2015). All three fungal species are necrotrophs with wide host ranges among cucurbits (Chiu and Walker 1949; Keinath 2011; Stewart et al. 2015) affecting aboveground, vegetative structures at any growth stage after seed germination (Wiant 1945). The three Stagonosporopsis species are pathogenic to cucurbits with similar virulence; however, $S$. caricae is also pathogenic to papaya (Stewart et al. 2015), causing fruit and stem rot and leaf spot of papaya. Until recently, only $S$. citrulli was recovered from GSB-infected cucurbits in the southeastern United States (Stewart et al. 2015). In 2013, four of 246 GSB fungi sampled from four watermelon fields in the southeastern United States were identified as S. caricae (Li and Brewer 2016). The four $S$. caricae isolates came from a single field in Tift County, Georgia. In 2014, 15 of 76 GSB fungi sampled from a single watermelon field in Cook County, Georgia were identified as $S$. caricae (Li and Brewer 2016).

Cultivars of watermelon (Citrullus lanatus), cucumber (Cucumis sativus), or muskmelon (Cucumis melo) resistant to Stagonosporopsis species are not currently available (Keinath 2014), so management of GSB requires both cultural and chemical control strategies. It is recommended that growers use only certified pathogen-free seed and seedlings (Sitterly and Keinath 1996). To limit local survival of

Corresponding Author: M. T. Brewer; E-mail address: mtbrewer@uga.edu

Accepted for publication 23 May 2016.

http://dx.doi.org/10.1094/PDIS-03-16-0341-RE

(C) 2016 The American Phytopathological Society
GSB fungi on debris, a minimum 2-year rotation with noncucurbit crops is recommended (Keinath 1996, 2000). Other cultural practices include incorporation of infested residue to reduce survival on plant debris (Sitterly and Keinath 1996), avoidance of overhead irrigation to reduce periods of leaf wetness (Thomas et al. 2012b), and soil fumigation with cabbage residue amendments (Keinath 1996). Nonetheless, fungicide application is by far the most effective option for GSB management (Keinath 2000, 2012; Thomas 2012b). Unfortunately, GSB fungi in the southeastern United States have repeatedly and rapidly evolved resistance to several classes of fungicides. In the mid-1990s, thiophanate-methyl, a methyl benzimidazole carbamate (MBC) fungicide (Fungicide Resistance Action Committee, FRAC \#1) (FRAC 2016), was deemed ineffective against GSB due to the development of resistance in pathogen populations (Keinath and Zitter 1998). Initially, azoxystrobin, a quinone outside inhibitor (QoI) fungicide (FRAC \#11), provided excellent control of GSB, but by the end of 1990s, cases of resistance appeared in Georgia (Stevenson et al. 2004) and South Carolina (Keinath 2009). Boscalid, a succinate dehydrogenase inhibitor (SDHI) fungicide (FRAC \#7), provided control for GSB until 2007 (Seebold and Langston 2003), when widespread resistance developed in Georgia (Thomas et al. 2012a) and South Carolina (Keinath 2012). GSB fungi remain sensitive to triazoles, the largest subgroup of demethylation inhibitors (DMI) (FRAC \#3) (Keinath and Hansen 2013; Thomas et al. 2012b). DMI fungicides inhibit ergosterol biosynthesis by targeting lanosterol $14 \alpha$-demethylase, which is encoded by the gene Cyp51 (Kuck et al. 2002). Triazoles are used against a broad spectrum of fungi in medical and agricultural settings (Moore et al. 2000; Price et al. 2015; van den Bossche et al. 2003).

In Georgia (Langston 2014), Florida (Dufault and Paret 2014), and South Carolina (Keinath and Miller 2014), management of GSB relies on triazoles, which is concerning, because resistance to triazoles has been observed for many other plant-pathogenic fungi (Cools et al. 2013; Price et al. 2015). However, unlike the qualitative resistance observed for single-site fungicides such as azoxystrobin, resistance to triazoles is quantitative, often resulting in development of a continuum of resistance phenotypes (Cools and Fraaije 2013). Mechanisms of resistance to triazoles include: (i) single-site mutations in the coding region of Cyp51 leading to changes in the amino acid sequence of the protein, making it unrecognizable by the fungicide (Cools et al. 2011; Frenkel et al. 2015; Schmitz et al. 2014), (ii) 
overexpression of Cyp51 due to changes in the promoter region (Cools et al. 2012; Schnabel and Jones 2001) or other unknown enhancers of transcription (Bolton et al. 2012; Ma and Tredway 2013), (iii) multiple copies of Cyp51 genes (Brunner et al. 2016), and (iv) overexpression of transporters that control the efflux of fungicides (Kretschmer et al. 2009). Common transporter groups include ATPbinding cassette $(\mathrm{ABC})$ transporters and major facilitator superfamily (MFS) transporters (Cools et al. 2013). The objectives of this study were to determine if resistance to triazole fungicides has developed in field populations of GSB fungi in the southeastern United States, and, if so, to investigate the molecular basis of triazole resistance in GSB fungi.

\section{Materials and Methods}

Isolates of GSB fungi. A total of 322 fungal isolates was collected from five watermelon (Citrullus lanatus) fields in Georgia, Florida, and South Carolina in July 2013 and 2014 (Table 1). There were 53 isolates sampled from a field in Cook County, Georgia in 2013; 76 isolates sampled from Cook County, Georgia in 2014; 99 isolates sampled from Tift County, Georgia in 2013; 72 isolates sampled from Suwannee County, Florida in 2013; and 22 isolates sampled from Colleton County, South Carolina in 2013 (Table 1). The detailed sampling methods and isolation procedures for these fungi have been described previously ( $\mathrm{Li}$ and Brewer 2016). Nineteen of the field isolates were previously identified as $S$. caricae, while the remaining 303 isolates were identified as S. citrulli (Brewer et al. 2015; Li and Brewer 2016). In addition, twelve GSB or papaya fruit rot isolates, including three $S$. citrulli, three $S$. cucurbitacearum, and six $S$. caricae isolates, were screened for resistance (Table 1). These isolates were collected from different cucurbit-growing regions across the United States, from South America, and from additional hosts, including cucumber ( $\mathrm{Cucu}$ mis sativus), muskmelon (Cucumis melo), butternut squash (Cucurbita moschata), and papaya (Carica papaya) (Stewart et al. 2015). All isolates were recovered on quarter-strength potato dextrose agar (qPDA) from filter paper maintained at $-20^{\circ} \mathrm{C}$. In total, $306 \mathrm{~S}$. citrulli isolates, three $S$. cucurbitacearum isolates, and $25 \mathrm{~S}$. caricae isolates were tested for tebuconazole sensitivity.
Fungicide sensitivity assay. Tebuconazole was selected to determine triazole sensitivity because it is widely used for GSB management in the southeastern United States. We used an in vitro mycelial growth assay developed by Thomas et al. (2012a) that compares mycelial growth on a tebuconazole-amended medium $(3.0 \mu \mathrm{g} / \mathrm{ml})$ with mycelial growth on a control medium. Technical grade tebuconazole (97.5\% active ingredient; Bayer CropScience, Kansas City, MO) was dissolved in acetone to obtain a stock solution of $30 \mathrm{mg} / \mathrm{ml}$. A $10 \times$ dilution of the stock solution was prepared in $1 \mathrm{ml}$ of acetone and was added to 1 liter of autoclaved, cooled PDA to obtain a concentration of $3.0 \mu \mathrm{g}$ of tebuconazole per milliliter. A control medium was prepared by adjusting PDA to a final acetone concentration of $0.1 \%$ by volume.

For each isolate, 5-mm diameter mycelial plugs were obtained from the edge of a 1-week-old colony, using a cork borer, and were placed in petri dishes of tebuconazole-amended and control media. Isolates were incubated in the dark at $25^{\circ} \mathrm{C}$ for 4 days. Mycelial growth was estimated as the average diameter of the colony less $5 \mathrm{~mm}$ for the mycelial plug. The relative growth (RG) for each isolate was calculated as the ratio of mycelial growth on the tebuconazoleamended medium to the mycelial growth on the control medium. Based on the previously developed assay (Thomas et al. 2012a), a phenotype of resistant to tebuconazole was assigned to GSB isolates with $\mathrm{RG}$ values greater than $25 \%$ and sensitive to tebuconazole was assigned to isolates with RG values less than $25 \%$. We observed that resistant isolates could be further divided into two phenotypic categories, which consisted of highly resistant isolates with RG values greater than $75 \%$ and moderately resistant isolates with RG from 25 to $75 \%$. The mycelial growth assay was repeated for isolates with highly resistant and moderately resistant phenotypes.

Identification of Cyp51 in draft genomes of Stagonosporopsis species. Draft genomes of nine GSB or papaya fruit rot isolates including three $S$. citrulli, three $S$. cucurbitacearum, and three $S$. caricae were assembled. A high quality DNA extraction method (Fulton et al. 1995) was used. Cetyl trimethylammonium bromide (CTAB) lysis buffer was prepared by mixing $6.5 \mathrm{ml}$ of buffer A ( $0.35 \mathrm{M}$ sorbitol, $0.1 \mathrm{M}$ Tris- $\mathrm{HCl}, \mathrm{pH}$ 9, and $5 \mathrm{mM}$ EDTA, $\mathrm{pH} 8), 6.5 \mathrm{ml}$ of buffer B (0.2 M Tris-HCl, $\mathrm{pH}$ 9, 50 mM EDTA, $\mathrm{pH}$ 8, $2 \mathrm{M} \mathrm{NaCl}, 2 \%$ CTAB),

Table 1. Resistance or sensitivity to tebuconazole for isolates of Stagonosporopsis spp. causing gummy stem blight of cucurbits or fruit rot of papaya

\begin{tabular}{|c|c|c|c|c|}
\hline Species (isolate) & Sampling location (year ${ }^{\mathbf{a}}$ ) & Original host & $\begin{array}{l}\text { No. of } \\
\text { isolates }\end{array}$ & Tebuconazole phenotype ${ }^{b}$ \\
\hline \multicolumn{5}{|l|}{ Field isolates } \\
\hline S. citrulli & Cook Co., Georgia (2013) & Watermelon (Citrullus lanatus) & 53 & $\mathrm{~S}$ \\
\hline S. citrulli & Tift Co., Georgia (2013) & Watermelon & 95 & $\mathrm{~S}$ \\
\hline S. citrulli & Suwannee Co., Florida (2013) & Watermelon & 72 & $\mathrm{~S}$ \\
\hline S. citrulli & Colleton Co., South Carolina (2013) & Watermelon & 22 & $\mathrm{~S}$ \\
\hline S. citrulli & Cook Co., Georgia (2014) & Watermelon & 61 & $\mathrm{~S}$ \\
\hline S. caricae & Tift Co., Georgia (2013) & Watermelon & 2 & HR \\
\hline S. caricae & Tift Co., Georgia (2013) & Watermelon & 2 & MR \\
\hline S. caricae & Cook Co., Georgia (2014) & Watermelon & 14 & HR \\
\hline S. caricae & Cook Co., Georgia (2014) & Watermelon & 1 & MR \\
\hline \multicolumn{5}{|l|}{ Isolates with sequenced genomes } \\
\hline S. citrulli (C5-5) & Tift Co., Georgia (2010) & Watermelon & 1 & $\mathrm{~S}$ \\
\hline S. citrulli (DIDYNY) & Onondaga Co., New York (N.A.) & Muskmelon (Cucumis melo) & 1 & $\mathrm{~S}$ \\
\hline S. citrulli (AcSq5) & Johnson Co., North Carolina (2000) & Acorn squash (Cucurbita pepo) & 1 & $\mathrm{~S}$ \\
\hline S. cucurbitacearum (RT2) & Michigan (1997) & Butternut squash (Cucurbita moschata) & 1 & $\mathrm{~S}$ \\
\hline S. cucurbitacearum (GSB26) & Tompkins Co., New York (1992) & Muskmelon & 1 & $\mathrm{~S}$ \\
\hline S. cucurbitacearum (GSB29) & New York (1992) & Watermelon & 1 & $\mathrm{~S}$ \\
\hline S. caricae (RG3) & California (N.A.) & Watermelon & 1 & $\mathrm{~S}$ \\
\hline S. caricae (ATCC5257) & Hawaii (N.A.) & Papaya (Carica papaya) & 1 & $\mathrm{~S}$ \\
\hline S. caricae $(\mathrm{C} 166)$ & Michigan (N.A.) & Cucumber (Cucumis sativus) & 1 & $\mathrm{~S}$ \\
\hline \multicolumn{5}{|l|}{ Other $S$. caricae isolates } \\
\hline S. caricae (2245) & Brazil (N.A.) & Unknown cucurbit & 1 & HR \\
\hline S. caricae (CBS102399) & Brazil (N.A.) & Papaya & 1 & $\mathrm{~S}$ \\
\hline S. caricae (CBS248.90) & Chile (N.A.) & Papaya & 1 & $\mathrm{~S}$ \\
\hline
\end{tabular}

a N.A. indicates that the sampling year was unknown.

b $\mathrm{S}$ indicates sensitive (relative growth $(\mathrm{RG})<25 \%)$, MR indicates moderately resistant $(25 \%<\mathrm{RG}<75 \%)$, and $\mathrm{HR}$ indicates highly resistant $(\mathrm{RG}>75 \%)$, based on in vitro mycelial growth assay on tebuconazole-amended media. 
$2.6 \mathrm{ml}$ of buffer C (5\% sarkosyl), $1.75 \mathrm{ml}$ of polyvinylpyrrolidone $(0.1 \%)$, and $1.25 \mu \mathrm{l}$ proteinase K. Approximately $500 \mathrm{mg}$ of mycelium growing at $25^{\circ} \mathrm{C}$ in the dark for 7 days on qPDA covered with sterile cellophane was removed and added to CTAB lysis buffer. The mixture was agitated with two 5-mm glass beads (VWR Soda Lime, Radnor, PA) at 1,750 rpm for $2 \mathrm{~min}$ in a 2010 Geno/Grinder (SPEX SamplePrep, Metuchen, NJ). The mixture was then inverted 10 times after adding $5.75 \mathrm{ml}$ of potassium acetate $(5 \mathrm{M})$, and was incubated on ice for $30 \mathrm{~min}$, followed by centrifugation for $20 \mathrm{~min}$ at $14,000 \times \mathrm{g}$. The supernatant was added to one volume of chloroform-isoamylalcohol ( $\mathrm{vol} / \mathrm{vol} 24: 1$ ), followed by centrifugation for $10 \mathrm{~min}$ at $14,000 \times \mathrm{g}$. The supernatant was added to $100 \mu \mathrm{l}$ of RNase A $(10 \mathrm{mg} / \mathrm{ml})$ and was incubated at $37^{\circ} \mathrm{C}$ for $120 \mathrm{~min}$. An equal volume of isopropanol and $1 / 10$ volume of sodium acetate was added; the mixture was then incubated at $25^{\circ} \mathrm{C}$ for $5 \mathrm{~min}$, followed by centrifugation at $14,000 \times g$ for $30 \mathrm{~min}$. The supernatant was discarded and the pellet was dissolved in $100 \mu \mathrm{l}$ of deionized $\mathrm{H}_{2} \mathrm{O}$, after being rinsed twice with $70 \%$ ethanol and air-dried.

Genomic DNA for each isolate was submitted to the Georgia Genomics Facility (Athens, GA) for next-generation sequencing library preparation, followed by sequencing reactions using the Illumina MiSeq platform according to the PE300 protocol (Illumina Inc., San Diego, CA). Files of the forward and reverse reads of each isolate with optimal $k$-mer values of 64 (substrings of length $k$ in DNA sequence data) were assembled de novo into draft genomes, using ABySS v.1.3.6 (Simpson et al. 2009) on the Georgia Advanced Computing Resource Center Linux cluster.

Nucleotide sequence of the Cyp51 gene from the annotated genome of Didymella exigua (scaffold 10: 784720-786692) (Nordberg et al. 2014) and paralogs in the genomes of Gibberella zeae (GenBank accession numbers FJ216393 and FJ216400) (Yin et al. 2009) and Aspergillus fumigatus (GenBank accession numbers AF338659 and AF338660) (Mellado et al. 2001) were used to search for homologs in each draft genome of the nine GSB isolates, using megaBLAST (Altschul et al. 1990). With pairwise megaBLAST, the Cyp51 regions identified in GSB isolates and from the D. exigua genome were compared with paralogs from $G$. zeae and A. fumigatus.

Sequencing of Cyp51 from Stagonosporopsis caricae. The Cyp51 genes from 19 isolates of $S$. caricae were aligned and compared. In addition to the sequences identified in the three draft genomes of tebuconazole-sensitive $S$. caricae isolates (Table 1), 16 isolates were polymerase chain reaction (PCR)-amplified and sequenced including: 11 isolates highly resistant to tebuconazole (GA6057 and GA6081 from Tift County, Georgia, sampled in 2013; GA8002, GA8007, GA8016, GA8036, GA8051, GA8061,
GA8091, and GA8098 from Cook County, Georgia, sampled in 2014; and 2245 from Brazil), three isolates moderately resistant to tebuconazole (GA6011 and GA6074 from Tift County, Georgia, sampled in 2013; GA8025 from Cook County, Georgia, sampled in 2014), and two isolates sensitive to tebuconazole (CBS102399 from Brazil and CBS248.90 from Chile). Genomic DNA was extracted from fresh mycelium, using a method modified from Lee et al. (1988). Approximately $100 \mathrm{mg}$ of mycelium from each isolate was harvested, after incubation at $25^{\circ} \mathrm{C}$ in the dark for 4 days, by removing the mycelium from qPDA covered with sterile cellophane. The mycelium was mixed with $1 \mathrm{ml}$ of mini-prep lysis buffer $(50 \mathrm{mM}$ EDTA, $\mathrm{pH} \mathrm{8,} 100 \mathrm{mM}$ Tris, $\mathrm{pH} \mathrm{8,} \mathrm{3.5 \%} \mathrm{sodium} \mathrm{dodecyl} \mathrm{sulfate,}$ $500 \mu \mathrm{g}$ of proteinase $\mathrm{K}$ per milliliter, and $1 \%$ sodium bisulfite) by vortexing for $1 \mathrm{~min}$. The mixture was then incubated for $15 \mathrm{~min}$ at $65^{\circ} \mathrm{C}$, followed by centrifugation for $5 \mathrm{~min}$ at $14,000 \times g$. The supernatant was added to $200 \mu \mathrm{l}$ of ammonium acetate $(7.5 \mathrm{M})$, and was vortexed for $10 \mathrm{~s}$. The mixture was placed on ice for $15 \mathrm{~min}$, and then, was centrifuged at $14,000 \times g$ for $3 \mathrm{~min}$. The supernatant was precipitated with an equal volume of isopropanol and was centrifuged at $14,000 \times g$ for $5 \mathrm{~min}$. The pellet was then resuspended in $100 \mu \mathrm{l}$ of sterilized deionized $\mathrm{H}_{2} \mathrm{O}$, after rinsing twice with $70 \%$ ethanol and air-drying. The DNA was stored at $-20^{\circ} \mathrm{C}$.

Based on the Cyp51 sequence from the draft genome of S. caricae, two pairs of primers were designed, using Primer3 (Rozen and Skaletsky 2000), to amplify the promoter and coding regions of Cyp51 (Table 2). PCR was conducted using a $20-\mu l$ volume reaction, prepared with reagents from TaKaRa Bio Inc. (Otsu, Japan): $3.5 \mu$ l of $10 \times$ buffer, $3.0 \mu \mathrm{l}$ of dNTP mixture $(2.5 \mathrm{mM}), 5 \mu \mathrm{l}$ of TaKaRa ExTaq $(5 \mathrm{U} / \mu \mathrm{l}), 1.5 \mu \mathrm{l}$ of each pair of primers $(10 \mu \mathrm{M})$, and $1 \mu \mathrm{l}$ of template DNA ( 3 to $20 \mathrm{ng}$ ). The thermal cycling conditions were initial denaturation at $94^{\circ} \mathrm{C}$ for $5 \mathrm{~min}$, followed by 35 cycles of denaturation at $94^{\circ} \mathrm{C}$ for $30 \mathrm{~s}$, annealing at $57^{\circ} \mathrm{C}$ for $30 \mathrm{~s}$, and extension at $72^{\circ} \mathrm{C}$ for $2 \mathrm{~min}$, with a final extension step at $72^{\circ} \mathrm{C}$ for $10 \mathrm{~min}$. PCR products were prepared for sequencing using USB ExoSAP-IT (Affymetrix, Inc., Cleveland, $\mathrm{OH}$ ) according to the manufacturer's protocol. To cover the entire promoter and coding regions of Cyp51, six primers were designed for the sequencing reactions (Table 2). Sequencing reactions for each isolate were prepared by mixing $1 \mu l$ of prepared PCR products and $1 \mu l$ of each sequencing primer $(3.3 \mu \mathrm{M})$. Products were submitted to the Georgia Genomics Facility, where sequencing reactions were conducted using Big Dye terminator chemistry and Ampli-Taq-FS DNA polymerase, followed by electrophoresis on a 3730x1 96-capillary DNA analyzer (Applied Biosystems, Foster City, CA). The sequences of the Cyp51 genes and upstream regions were aligned using Geneious 7.0.6 (Biomatters

Table 2. Nucleotide sequence and purpose of primers used in this study

\begin{tabular}{|c|c|c|}
\hline Primer & Sequence & Purpose \\
\hline ScCyp51_F-175 & 5'-TTTATCGCCCGATCTGCTCC-3' & $\begin{array}{l}\text { Amplification of Cyp } 51 \text { coding region } \\
\text { Sequencing of Cyp } 51 \text { coding region }\end{array}$ \\
\hline ScCyp51_R1774 & 5'-TAACACACCAGGTAGTGCGG-3' & $\begin{array}{l}\text { Amplification of Cyp } 51 \text { coding region } \\
\text { Sequencing of Cyp } 51 \text { coding region }\end{array}$ \\
\hline ScCyp51u_F-1314 & 5'-TAACCACCGTCGCTACACAC-3' & $\begin{array}{l}\text { Amplification of Cyp } 51 \text { promoter region } \\
\text { Sequencing of Cyp } 51 \text { promoter region }\end{array}$ \\
\hline ScCyp51u_R215 & 5'-GGGTCCATGCCATAGGTGAC-3' & $\begin{array}{l}\text { Amplification of Cyp } 51 \text { promoter region } \\
\text { Sequencing of Cyp } 51 \text { promoter region }\end{array}$ \\
\hline ScCyp51_F289 & 5'-GAGGCAACGCGCTGACTC-3' & Sequencing of Cyp 51 coding region \\
\hline ScCyp51_F590 & 5'-GCACTCCGCTCCTACGTTAC-3' & Sequencing of Сyp 51 coding region \\
\hline ScCyp51_R1055 & 5'-CCAGGCGAAGGAGAATCCAA-3' & Sequencing of Cyp 51 coding region \\
\hline ScCyp51_R1390 & 5'-AGCTTCTGGTTCTTCCTCTTTGT-3' & Sequencing of Cyp 51 coding region \\
\hline ScCyp51u_F-839 & 5'-GGTGCCACGAAGATGCTGAA-3' & Sequencing of Cyp 51 promoter region \\
\hline ScCyp51u_R-188 & 5'-GCGATAAACTGACGACACGC-3' & Sequencing of Cyp 51 promoter region \\
\hline ScCyp51_F1212 & 5'-CACGCACCCATTCACTCCATT-3' & Determining expression level of Cyp 51 \\
\hline ScCyp51_R1321 & $5^{\prime}$-GAGAAGCCAGGCGAAGACATC-3' & Determining expression level of Cyp 51 \\
\hline ScAct_F & 5'-CTCCCATCAACCCCAAGTCCA-3' & Determining expression level of Actin \\
\hline ScAct_R & 5'-CAGCCTGGATGGAGACGTAGA-3' & Determining expression level of Actin \\
\hline ScAtrG_F & 5'-ACTGCTACTCCTAGCCAAGGGT-3' & Determining expression level of AtrG \\
\hline ScAtrG_R & 5'-GTCTGACCGTTGTCACCGATG-3' & Determining expression level of $\operatorname{Atr} G$ \\
\hline
\end{tabular}


Ltd., Auckland, New Zealand). The sequences from resistant isolates and moderately resistant isolates were compared with sequences from sensitive isolates to identify polymorphic sites responsible that were associated with tebuconazole resistance. Polymorphic sites in the coding regions were identified as synonymous (same amino acid) or nonsynonymous (different amino acid).

RNA extraction and reverse transcription. Twelve isolates were selected to measure expression levels of Cyp51 and ScAtrG (an ABC transporter gene). These isolates included four $S$. caricae isolates highly resistant to tebuconazole (GA8007 and GA8016 from Cook County, Georgia, sampled in 2014, and 2245, sampled from Brazil) or moderately resistant to tebuconazole (GA6074 from Tift County Georgia, sampled in 2013), and four S. caricae isolates sensitive to tebuconazole (C166, RG3, ATCC5257, and CBS102399). For comparison among GSB species, expression levels were measured in two sensitive $S$. citrulli isolates (GA8073 from Cook County, Georgia, sampled in 2014, and C5-5) and two sensitive S. cucurbitacearum isolates (GSB26 and RT2).

Approximately $100 \mathrm{mg}$ of fresh mycelium of each isolate was harvested from PDA amended with tebuconazole $(0.3 \mu \mathrm{g} / \mathrm{ml})$, after incubating at $25^{\circ} \mathrm{C}$ in the dark for 7 days, by removing the mycelium from PDA covered with sterile cellophane. Mycelium was added to PureLink lysis buffer (Life Technologies, Carlsbad, CA) containing 1\% 2-mercaptoethanol. Two 5-mm glass beads were added to each tube, and the mixtures were homogenized at $1,750 \mathrm{rpm}$ for $2 \mathrm{~min}$, using a 2010 Geno/Grinder. The manufacturer's instructions for the PureLink RNA mini kit were followed for extraction of total RNA from each isolate. The RNA quality was determined by electrophoresis on a $1 \%$ (wt/vol) agarose gel and the concentration was measured, using a Spectrophotometer ND-1000 (NanoDrop Technologies, Inc., Wilmington, DE).

Reverse transcription was carried out with a PrimerScript RT reagent kit (TaKaRa Bio Inc.). The genomic DNA elimination reaction required a $15-\mu l$ volume mixture containing $3.5 \mu l$ of RNA extract (1-2 ng), $3 \mu \mathrm{l}$ of $5 \times \mathrm{gDNA}$ eraser buffer, and $1.5 \mu \mathrm{l}$ of gDNA eraser. The mixture was incubated at $42^{\circ} \mathrm{C}$ for $2 \mathrm{~min}$. Reverse transcription was conducted in a $30-\mu l$ volume containing $15 \mu \mathrm{l}$ of gDNA elimination reaction solution from the previous step, $4.5 \mu \mathrm{l}$ of $5 \times$ PrimeScript buffer 2, $1.5 \mu \mathrm{l}$ of PrimeScript RT enzyme mix I, and $1.5 \mu \mathrm{l}$ of RT primer mix. The mixture was incubated at $37^{\circ} \mathrm{C}$ for $15 \mathrm{~min}$, followed by $85^{\circ} \mathrm{C}$ for $2 \mathrm{~s}$. The complementary DNA (cDNA) was stored at $-20^{\circ} \mathrm{C}$. To replicate the experiment, the same 12 isolates were grown a second time, then, the RNA was extracted and reverse transcribed to cDNA as described above.

Expression level of $C y p 51$ and $S c A t r G$ by real-time PCR. A pair of primers (Table 2) with $100 \%$ similarity to all three species was developed for amplification of a 110-bp fragment of Cyp51 for realtime PCR. Actin, a gene with a constant expression level, was used as an internal control in the real-time PCR. Actin was identified in the draft genomes of the nine GSB fungi by MegaBLAST with the homolog from Didymella rabiei (GenBank accession KM244530) (Kim et al. 2015). Primers (Table 2) with $100 \%$ similarity to all three GSB species were designed to amplify a 93-bp fragment of Actin.

To investigate if increased fungicide efflux from the cell by a transporter was associated with tebuconazole resistance in S. caricae, the expression levels of a transporter gene were measured by real-time PCR. Using homologs of transporter genes in Botrytinia fuckeliana, the draft genomes of nine GSB isolates were searched by megaBLAST. The genes included two ABC transporters, BcatrB (GenBank accession AJ006217) (Schoonbeek et al. 2001) in the pleiotropic drug resistance (ABC-G) group and BcatrD (GenBank accession AJ272521) (Hayashi et al. 2001) in the multidrug resistance (ABC-B) group, and one type of MFS transporter, MfsM2 (GenBank accession CQ292707) (Kretschmer et al. 2009). Only a homolog of the pleiotropic drug resistance group

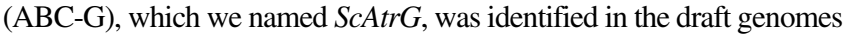
of GSB fungi. A set of primers (Table 2) with $100 \%$ similarity to the three Stagonosporopsis species was designed for the amplification of a 66-bp fragment of ScAtrG by real-time PCR.

Real-time PCR reactions were conducted to detect the expression levels of Cyp51, ScAtrG, and Actin on 12 GSB isolates, using the StepOnePlus Real-Time PCR system (Life Technologies). Three technical replicate reactions were conducted for each gene for each of the 12 isolates. Each reaction was conducted in $20-\mu$ l volumes containing $2.0 \mu \mathrm{l}$ of cDNA template, $10.0 \mu \mathrm{l}$ of Power SYBR green PCR master mix (Life Technologies), $1.0 \mu \mathrm{l}$ of forward primer, and $1.0 \mu \mathrm{l}$ of reverse primer. The 'two-step' cycling conditions were an initial heating at $95^{\circ} \mathrm{C}$ for $10 \mathrm{~min}$, followed by 40 cycles of $95^{\circ} \mathrm{C}$ for $15 \mathrm{~s}$ and $60^{\circ} \mathrm{C}$ for $1 \mathrm{~min}$, and a final heating at $95^{\circ} \mathrm{C}$ for $15 \mathrm{~s}$. The cycle threshold $\left(C_{t}\right)$ value of each reaction was recorded as the expression level. The expression level of each gene for each isolate was calculated as the mean $C_{t}$ value of the three technical replicates, when the standard error of the three $C_{t}$ values was less than 0.5 . The mean $C_{t}$ values of $C y p 51$ and $S c A t r G$ were standardized by the mean $C_{t}$ values of the internal control Actin to determine the relative expression level of Cyp51 and ScAtrG. All steps from isolate growth to real-time PCR were repeated a second time. Analysis of variance was conducted using JMP Pro v11 (SAS Institute, Cary, NC) to identify significant differences in expression level between tebuconazoleresistant and tebuconazole-sensitive isolates.

\section{Results}

Differences in tebuconazole sensitivity of Stagonosporopsis species. All 303 S. citrulli isolates collected from the southeastern United States in 2013 and 2014 were found to be sensitive to tebuconazole (Table 1). All S. caricae isolates from the southeastern United States were moderately $(n=3)$ or highly $(n=16)$ resistant to tebuconazole (Table 1). The S. caricae isolate from Brazil was highly resistant to tebuconazole. All other GSB or papaya fruit rot Stagonosporopsis isolates assayed were sensitive to tebuconazole, including nine $S$. caricae isolates originally collected from outside the southeastern United States.

Cyp51 gene sequence and primer pairs. The numbers of contigs with a minimum length of $200 \mathrm{bp}$ varied from 2,275 in S. caricae isolate RG3 to 7,991 in S. cucurbitacearum isolate GSB26. The Cyp51 gene was 1,676 bp in length (Fig. 1) and contained three exons (246, 198 , and 1,134 bp) and two introns (50 and $48 \mathrm{bp}$ ) (GenBank accessions KU847917 to KU847921). The Cyp51 genes identified in the GSB or papaya fruit rot fungi and D. exigua were homologous to $C y p 51 B$ of $G$. zeae and A. fumigatus. The homologs of Cyp51A of $G$. zeae and A. fumigatus were not detected in the nine draft genomes or the complete genome of D. exigua. A total of 1,314 bp of the upstream promoter region was sequenced.

Cyp51 sequence variation among $S$. caricae. The Cyp 51 genes from 11 highly tebuconazole-resistant $S$. caricae isolates, three moderately resistant isolates and two tebuconazole-sensitive isolates were sequenced and were compared with sequences from the draft genomes of three tebuconazole-sensitive $S$. caricae isolates and two additional tebuconazole-sensitive isolates. There were five different haplotypes among the $S$. caricae isolates (Fig. 1). The upstream promoter region, the first exon, and both introns were identical among the haplotypes. Tebuconazole-sensitive isolates were represented by haplotypes 1 and 2. Haplotype 1 (GenBank accession KU847917), which had two synonymous substitutions in the third exon, was shared by two tebuconazole-sensitive isolates (C166 and ATCC5257). Haplotype 2 (GenBank accession KU847918), shared by nine highly tebuconazoleresistant isolates (GA6057, GA6081, GA8007, GA8016, GA8036, GA8051, GA8061, GA8091, and GA8098) and three sensitive isolates (RG3, CBS102399, and CSB248.90), was the most common. Highly resistant isolate GA8002 had haplotype 3 (GenBank accession KU847919), which contained a nonsynonymous substitution in the second exon (isoleucine [I] to threonine [T] at codon position 113). Haplotype 4 (GenBank accession KU847920) was shared by highly resistant isolate 2245 and moderately resistant isolate GA8025 and contained a nonsynonymous substitution in the third exon (glycine [G] to serine [S] at codon position 463). The other two moderately resistant isolates (GA6011 and GA6075) shared haplotype 5 (KU827921), which had one nonsynonymous substitution (alanine [A] to glycine [G] at codon position 464) in the third exon. None of the substitutions was associated with tebuconazole resistance.

No difference in expression levels of Cyp51 and ScAtrG between resistant and sensitive isolates. Using the expression level of Actin as an internal control, the induced expression levels of 
Cyp51 and ScAtrG for isolates were calculated by averaging the two experimental replicates, since there was no significant difference between experiments $(P=0.305$ for $C y p 51$ and $P=0.519$ for $S c A t r G)$ or isolate by experiment interaction $(P=0.539$ for $C y p 51$ and $P=$ 0.263 for $S c A t r G)$. For $C y p 51$, the relative expression levels among tebuconazole-resistant $S$. caricae $(\bar{x}=1.077)$, tebuconazole-sensitive S. caricae $(\bar{x}=1.003)$, and tebuconazole-sensitive $S$. citrulli $(\bar{x}=$ $1.057)$ and $S$. cucurbitacearum $(\bar{x}=0.993)$ were not significantly different (Fig. 2A). There were no significant differences in expression levels between the three resistant $S$. caricae isolates and the moderately resistant $S$. caricae isolate. In addition, the average expression levels of the ABC transporter $S c A t r G$ for the four isolates were also similar, with no significant differences detected among tebuconazole-resistant S. caricae $(\bar{x}=1.307)$, tebuconazole-sensitive $S$. caricae $(\bar{x}=1.354)$, and tebuconazole-sensitive $S$. citrulli $(\bar{x}=1.080)$ and $S$. cucurbitacearum $(\bar{x}=1.287)$ isolates (Fig. 2B).

\section{Discussion}

Tebuconazole, a widely used triazole fungicide, is considered very effective in the management of GSB of cucurbits in the southeastern United States (Keinath and Hansen 2013; Thomas et al. 2012b). However, our identification of resistant isolates collected from watermelon fields in Georgia and observations of resistance in a field trial in Georgia (unpublished data) indicate that the efficacy of triazole fungicides in the southeastern United States could decline in the next few years. In a tebuconazole fungicide sensitivity assay, we identified 16 highly resistant (two from Tift County in 2013 and 14 from Cook County in 2014) and three moderately resistant (two from Tift County in 2013 and one from Cook County in 2014) GSB isolates. One isolate from Brazil was also identified as highly resistant. All of the tebuconazole-resistant GSB isolates identified from the southeastern United States and Brazil were $S$. caricae and all S. caricae isolates from the southeastern United States were highly resistant or moderately resistant to tebuconazole. However, isolates of $S$. caricae sampled from watermelon in California, cucumber in Michigan, a cucurbit in Brazil, and papaya in Hawaii, Brazil, and Chile were sensitive to tebuconazole (Table 1), which indicates that $S$. caricae is not simply a more-resistant species overall. Although the date when the sensitive $S$. caricae isolates were sampled is unknown, they were all obtained prior to 2013 when tebuconazole resistance was first detected in isolates from Georgia. Stagonosporopsis citrulli, the dominant species causing GSB in the southeastern United States (Stewart et al. 2015), remains sensitive to tebuconazole. The three isolates of S. cucurbitacearum collected from regions outside the southeastern United States were also sensitive to tebuconazole.

Although $S$. citrulli and $S$. caricae are morphologically indistinguishable, distinct differences in tebuconazole sensitivity are evident
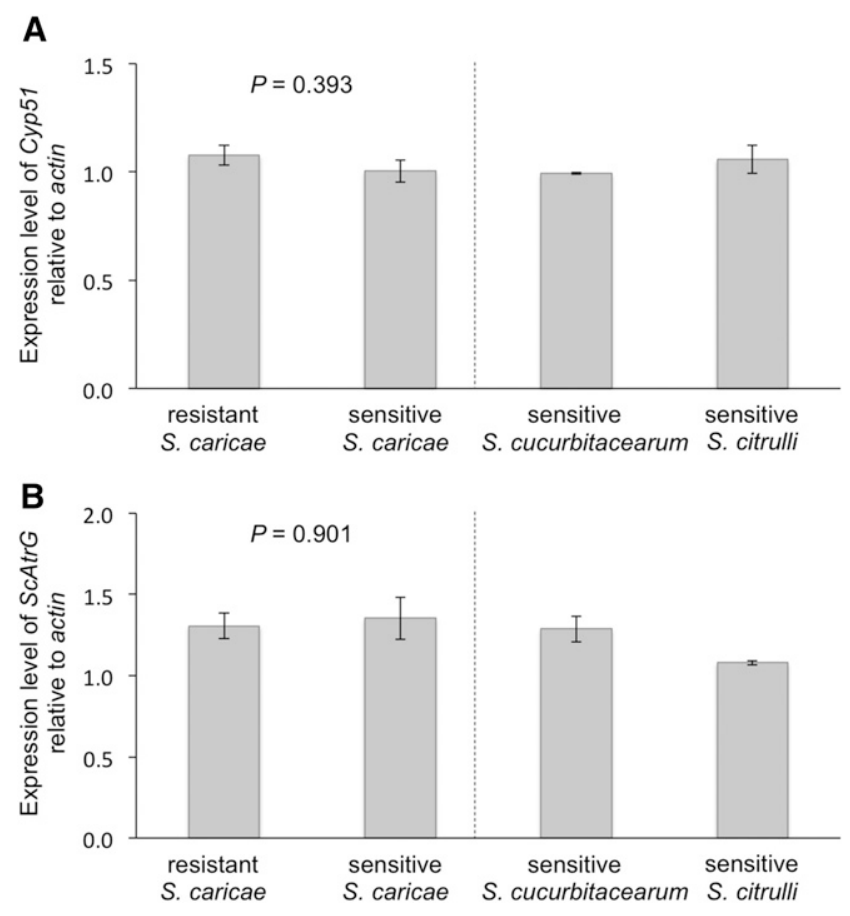

Fig. 2. Expression levels of A, Cyp51 and B, ScAtrG relative to Actin among gummy stem blight fungi after growing on media amended with tebuconazole $(0.3 \mu \mathrm{g} / \mathrm{ml})$ for 7 days. Error bars indicate the standard error of the four biological replicates of tebuconazole-resistant and four tebuconazole-sensitive Stagonosporopsis caricae isolates each averaged over two experiments, as well as two biological replicates of tebuconazole-sensitive $S$. citrulli and $S$. cucurbitacearum isolates averaged over two experiments. analysis of variance was conducted among four tebuconazole-resistant and four tebuconazole-sensitive isolates of $S$. caricae. The $P$ value is shown to the left of the dashed reference line.

$$
N=2(\mathrm{~S}=2)
$$

1.

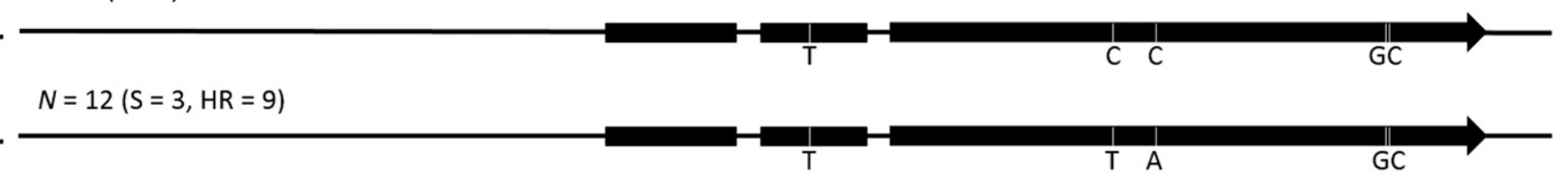

2.

3. $N=1(\mathrm{HR}=1)$

4.

$$
N=2(\mathrm{HR}=1, \mathrm{MR}=1)
$$

4.

$$
N=2(\mathrm{MR}=2)
$$

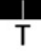

G463S

5.

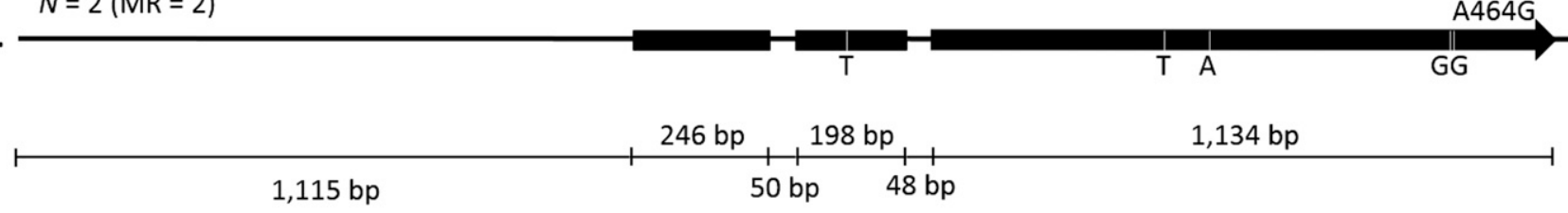

Upstream region

Coding region

Fig. 1. Schematic of the Cyp51 gene and upstream region of five genotypes from five tebuconazole-sensitive, 11 highly tebuconazole-resistant, and three moderately tebuconazoleresistant Stagonosporopsis caricae isolates. Total number of isolates $(N)$, and number of sensitive $(S)$, highly resistant (HR), and moderately resistant (MR) isolates with each genotype is shown. Black rectangles represent exons and arrows indicate the direction of transcription. Letters below the bars indicate polymorphic sites among the five genotypes. The amino acid locations of the putative protein for nonsynonymous substitutions are indicated above the bar. 
between these two species causing GSB in the southeastern United States. The decline in efficacy of MBC (Keinath and Zitter 1998), QoI (Keinath 2009; Stevenson et al. 2004), and SDHI (Keinath 2012; Thomas et al. 2012a) fungicides against GSB fungi resulted from increased frequency of resistant isolates due to strong selection pressure from each fungicide. It is not clear how or from where the tebuconazole-resistant $S$. caricae populations arose in the southeastern United States ( $\mathrm{Li}$ and Brewer 2016), but as tebuconazole use for GSB continues, it is possible that selection for resistant isolates of $S$. caricae with greater fitness could result in changes in the species composition of GSB fungi in the southeastern United States. Alternatively, tebuconazole-resistant $S$. caricae populations may be increasing as a result of introductions on cucurbit seed or from papaya.

We investigated the underlying genetic basis of tebuconazole resistance within $S$. caricae by comparing the nucleotide sequence of Cyp51 in resistant and sensitive isolates. Triazole molecules bind to lanosterol $14 \alpha$-demethylase (Kelly and Kelly 2013), and, therefore, a single-site mutation in Cyp51 causing an amino acid change in the enzyme is responsible for triazole resistance in several plantpathogenic fungi (Cools et al. 2011; Frenkel et al. 2015; Schmitz et al. 2014). We sequenced and compared the coding region $(1,676 \mathrm{bp})$ and promoter region $(1,314 \mathrm{bp})$ of Cyp 51 from 11 highly resistant, three moderately resistant, and five sensitive $S$. caricae isolates. The promoter regions were compared because insertions were found in the promoter regions of Cyp51 in other triazole-resistant plant pathogens (Cools et al. 2012; Schnabel and Jones 2001) that were responsible for increasing transcription. However, the promoter region, both introns, and the first exon were identical among sequences for all 19 isolates of $S$. caricae that were compared. Although there were polymorphic sites in the second and third exons, none of the haplotypes was clearly associated with the tebuconazole-resistant phenotype. Moreover, the most common haplotype was shared among resistant and sensitive isolates. Frequently reported mutational sites and amino acid substitutions identified in several other plant-pathogenic fungi, e.g., Y136F (Cools et al. 2013; Price et al. 2015), were not found in any of the tebuconazole-resistant $S$. caricae isolates. Thus, triazole resistance in $S$. caricae in the southeastern United States is not likely due to mutations in the Cyp51 gene or upstream promoter region.

Increased expression of Cyp51 is another mechanism for triazole resistance in fungi that we investigated in $S$. caricae. In addition to insertions in the promoter region of Cyp51 leading to increased expression (Cools et al. 2012; Schnabel and Jones 2001), other unknown transcriptional enhancing factors in triazole-resistant isolates may act on the promoter region of Cyp51 (Ma and Tredway 2013). After growing on tebuconazole-amended media for 7 days, the average expression levels of Cyp51 in tebuconazole-resistant $S$. caricae, tebuconazole-sensitive $S$. caricae, and other tebuconazolesensitive GSB fungi were not significantly different; therefore, gene duplication of Cyp51 and other unknown transporters may be responsible for the tebuconazole resistance of $S$. caricae.

Differences in expression of some transporters, which are integral proteins that move molecules including nutrients and secrete substrates such as toxic compounds across membranes (Perlin et al. 2014), has been identified as a mechanism of triazole fungicide resistance. Transporters in the ABC and MFS superfamilies are responsible for decreasing fungicide accumulation within cells of many pathogenic fungi (Price et al. 2015). The ABC transporter homolog ScAtrG, identified and investigated in $S$. caricae in this study, did not show significant increases in expression in tebuconazole-resistant isolates. Homologs of other transporters that could be involved in fungicide efflux from the cell were not readily identified in the draft genome sequence of $S$. caricae, but it is possible that an unidentified transporter or transporters may contribute to triazole resistance.

Another mechanism for triazole resistance identified in fungi is multiple copies of Cyp51 genes. Paralogs of Cyp51, designated as Cyp51A and Cyp51B, were first identified in the human pathogen Aspergillus fumigatus (Mellado et al. 2001). Both genes belonged to the lanosterol $14 \alpha$-demethylase family. In a study of plant-pathogenic fungi, Yin et al. (2009) found that tebuconazole induced the expression of both Cyp51A and Cyp51B in Fusarium asiaticum and
$F$. graminearum and determined that the sequences of Cyp $51 \mathrm{~A}$ were different between the two species. In another study of $F$. graminearum populations, polymorphism was found among Cyp51A sequences but not among Cyp51B sequences (Talas and McDonald 2015). Cyp51 homologs identified in D. exigua and the genomes of the three Stagonosporopsis species in this study were orthologous to the more conserved $C y p 51 B$ of $A$. fumigataus and $F$. graminearum. Paralogs of $C y p 51 B$, including Cyp51A, were not identified within the genomes of $D$. exigua (Mellado et al. 2001; Yin et al. 2009) or the three Stagonosporopsis species causing GSB. Interestingly, in recent studies of Rhynchosporium commune, three paralogs were identified, including Cyp51A, Cyp51B, and a pseudogene of Cyp51A designated as Cyp51A- , and the presence of Cyp51A was associated with triazole resistance (Brunner et al. 2016). Paralogs of Cyp51, including Cyp51A, could be present in resistant isolates of $S$. caricae and serve as a possible mechanism for tebuconazole resistance. The three draft genomes of $S$. caricae searched for Cyp51 homologs were all generated from triazolesensitive isolates, so it would be worthwhile to sequence the genome of a resistant isolate to scan for paralogs.

Although the one or more molecular mechanisms for resistance to triazoles in S. caricae is not clear, we can rule out some of the known resistance mechanisms identified in other fungi, and we now know that the underlying basis of resistance is more complex than originally hypothesized. Studies investigating additional mechanisms are warranted because knowledge of the molecular basis of resistance will inform us of the evolutionary processes leading to triazole resistance in GSB fungi and, possibly, allow us to develop a molecular marker to quickly and accurately monitor triazole resistance in field populations. Future approaches could include RNA-seq to identify genes that are expressed at higher levels in resistant isolates or if paralogs of Cyp51 are expressed. Recent work on Cercospora beticola identified 110 genes that were expressed at different levels in triazole-resistant isolates (Bolton et al. 2015). Until the molecular basis of resistance to triazoles is identified, the PCR-based marker for distinguishing Stagonosporopsis species causing GSB (Brewer et al. 2015) can be used to screen for $S$. caricae, which is more likely to be triazole-resistant and resistance can then be tested by fungicide sensitivity assays.

\section{Acknowledgments}

We thank C. Chan and N. Jiang for technical assistance. This project was supported by a grant from the Georgia Agricultural Commodity Commission for Vegetables.

\section{Literature Cited}

Altschul, S. F., Gish, W., Miller, W., Myers, E. W., and Lipman, D. J. 1990. Basic local alignment search tool. J. Mol. Biol. 215:403-410.

Bolton, M., Faino, L., Thomma, B., de Jonge, R., and Secor, G. 2015. Insight into DMI-resistance - RAN-seq analysis of Cercospora beticola DMI-resistant and -sensitive strains in response to tetraconazole. Phytopathology 105:17-18.

Bolton, M. D., Birla, K., Rivera-Varas, V., Rudolph, K. D., and Secor, G. A. 2012. Characterization of Cbcyp51 from field isolates of Cercospora beticola. Phytopathology 102:298-305.

Brewer, M. T., Rath, M., and Li, H.-X. 2015. Genetic diversity and population structure of the cucurbit gummy stem blight pathogen based on microsatellite markers. Phytopathology 105:815-824.

Brunner, P. C., Stefansson, T. S., Fountaine, J., Richina, V., and McDonald, B. A 2016. A global anylsis of CYP51 diversity and azole sensitivity in Rhynchosporium commune. Phytopathology 106:355-361.

Chiu, W. F., and Walker, J. C. 1949. Morphology and variability of the cucurbit black rot fungus. J. Agric. Res. 78:81-102.

Cools, H. J., Bayon, C., Atkins, S., Lucas, J. A., and Fraaije, B. A. 2012. Overexpression of the sterol $14 \alpha$-demethylase gene $(M g C Y P 51)$ in Mycosphaerella graminicola isolates confers a novel azole fungicide sensitivity phenotype. Pest Manag. Sci. 68:1034-1040.

Cools, H. J., and Fraaije, B. A. 2013. Update on mechanisms of azole resistance in Mycosphaerella graminicola and implications for future control. Pest Manag. Sci. 69:150-155.

Cools, H. J., Hawkins, N. J., and Fraaije, B. A. 2013. Constraints on the evolution of azole resistance in plant pathogenic fungi. Plant Pathol. 62 (S1):36-42.

Cools, H. J., Mullins, J. G. L., Fraaije, B. A., Parker, J. E., Kelly, D. E., Lucas, J. A., and Kelly, S. L. 2011. Impact of recently emerged sterol $14 \alpha$-demethylase (CYP51) variants of Mycosphaerella graminicola on azole fungicide sensitivity. Appl. Environ. Microbiol. 77:3830-3837. 
Dufault, N. S., and Paret, M. S. 2014. Watermelon spray guide 2015. IFAS Extension, Gainesville, FL.

FRAC. 2016. FRAC Code List 2016: Fungicides sorted by mode of action (including FRAC code numbering). Fungicide Resistance Action Committee, Brussels.

Frenkel, O., Cadle-Davidson, L., Wilcox, W. F., and Milgroom, M. G. 2015. Mechanisms of resistance to an azole fungicide in the grapevine powdery mildew fungus, Erysiphe necator. Phytopathology 105:370-377.

Fulton, T. M., Chunwongse, J., and Tanksley, S. D. 1995. Microprep protocol for extraction of DNA from tomato and other herbaceous plants. Plant Mol. Biol. Rep. 13:207-209.

Gusmini, G., Song, R., and Wehner, T. C. 2005. New sources of resistance to gummy stem blight in watermelon. Crop Sci. 45:582-588.

Hayashi, K., Schoonbeek, H., Sugiura, H., and de Waard, M. A. 2001. Multidrug resistance in Botrytis cinerea associated with decreased accumulation of the azole fungicide oxpoconazole and increased transcription of the $\mathrm{ABC}$ transporter gene BcatrD. Pestic. Biochem. Physiol. 70:168-179.

Keinath, A. P. 1996. Soil amendment with cabbage residue and crop rotation to reduce gummy stem blight and increase growth and yield of watermelon. Plant Dis. 80:564-570

Keinath, A. P. 2000. Effect of protectant fungicide application schedules on gummy stem blight epidemics and marketable yield of watermelon. Plant Dis. 84:254-260.

Keinath, A. P. 2009. Sensitivity to azoxystrobin in Didymella bryoniae isolates collected before and after field use of strobilurin fungicides. Pest Manag. Sci. 65:1090-1096.

Keinath, A. P. 2011. From native plants in Central Europe to cultivated crops worldwide: The Emergence of Didymella bryoniae as a cucurbit pathogen. HortScience 46:532-535.

Keinath, A. P. 2012. Differential sensitivity to boscalid in conidia and ascospores of Didymella bryoniae and frequency of boscalid-insensitive isolates in South Carolina. Plant Dis. 96:228-234.

Keinath, A. P. 2014. Differential susceptibility of nine cucurbit species to the foliar blight and crown canker phases of gummy stem blight. Plant Dis. 98: 247-254.

Keinath, A. P., Farnham, M. W., and Zitter, T. A. 1995. Morphological, pathological, and genetic differentiation of Didymella bryoniae and Phoma spp. isolated from cucurbits. Phytopathology 85:364-369.

Keinath, A. P., and Hansen, Z. R. 2013. Isolates of Didymella bryoniae from South Carolina remain sensitive to DMI fungicides despite multiyear exposure. J. Phytopathol. 161:315-323.

Keinath, A. P., and Miller, G. A. 2014. Watermelon spray guide for 2014. Clemson Cooperative Extension, Clemson, SC.

Keinath, A. P., and Zitter, T. A. 1998. Resistance to benomyl and thiophanatemethyl in Didymella bryoniae from South Carolina and New York. Plant Dis. $82: 479-484$

Kelly, S. L., and Kelly, D. E. 2013. Microbial cytochromes P450: Biodiversity and biotechnology. Where do cytochromes P450 come from, what do they do and what can they do for us? Philos. Trans. R. Soc. Lond. B Biol. Sci. 368:20120476.

Kim, W., Park, C.-M., Park, J.-J., Akamatsu, H. O., Peever, T. L., Xian, M., Gang, D. R., Vandemark, G., and Chen, W. 2015. Functional analyses of the dielsalderase gene sol5 of Ascochyta rabiei and Alternaria solani indicate that the solanapyrone phototoxins are not required for pathogenicity. Mol. PlantMicrobe Interact. 28:482-496.

Kretschmer, M., Leroch, M., Mosbach, A., Walker, A.-S., Fillinger, S., Mernke, D., Schoonbeek, H.-J., Pradier, J.-M., Leroux, P., de Waard, M. A., and Hahn, H. 2009. Fungicide-driven evolution and molecular basis of multidrug resistance in field populations of grey mould fungus Botrytis cinerea. PLoS Pathog 5:e1000696.

Kuck, K. H., Stenzl, K., and Vors, J.-P. 2002. Sterol biosynthesis inhibitors. Pages 761-805 in: Modern Crop Protection Compounds. $2^{\text {nd }}$ ed. Vol. 2: Fungicides. W. Krämer, U. Schirmer, P. Jeschke, and M. Witschel, ed. Wiley-VCH Verlag GmbH \& Co., Weinheim, Germany.

Langston, D. B., Jr. 2014. Watermelon fungicide spray programs 2014. UGA Extension, Athens, GA.

Lee, S. B., Milgroom, M. G., and Taylor, J. W. 1988. A rapid, high yield mini-prep method for isolation of total genomic DNA from Fungi. Fungal Genet. Newsl. 35:23-24

Li, H.-X., and Brewer, M. T. 2016. Spatial genetic structure and population dynamics of gummy stem blight fungi within and among watermelon fields in the southeastern United States. Phytopathology 106. Published online. doi: 10.1094/PHYTO-01-16-0006-R
Ma, B., and Tredway, L. P. 2013. Induced overexpression of cytochrome P450 sterol $14 \alpha$-demethylase gene (CYP51) correlates with sensitivity to demethylation inhibitors (DMIs) in Sclerotinia homoeocarpa. Pest Manag. Sci. 69:1369-1378.

Mellado, E., Diaz-Guerra, T. M., Cuenca-Estrella, M., and Rodriguez-Tudela, J. L. 2001. Identification of two different 14-alpha sterol demethylase-related genes (cyp51A and cyp51B) in Aspergillus fumigatus and other Aspergillus species. J. Clin. Microbiol. 39:2431-2438.

Moore, C. B., Sayers, N., Mosquera, J., Slaven, J., and Denning, D. W. 2000 Antifungal drug resistance in Aspergillus. J. Infect. 41:203-220.

NASS. 2015. Vegetables 2015 Summary. United States Department of Agriculture Washington, DC

Nordberg, H., Cantor, M., Dusheyko, S., Hua, S., Poliakov, A., Shabalov, I. Smirnova, T., Grigoriev, I. V., and Dubchak, I. 2014. The genome portal of the Department of Energy Joint Genome Institute: 2014 updates. Nucleic Acids Res. 42:D26-31.

Perlin, M. H., Andrews, J., and Toh, S. S. 2014. Essential letters in the fungal alphabet $\mathrm{ABC}$ and MFS transporters and their roles in survival and pathogenicity. Adv. Genet. 85:201-253.

Price, C. L., Parker, J. E., Warrilow, A. G. S., Kelly, D. E., and Kelly, S. L. 2015 Azole fungicides-Understanding resistance mechanisms in agricultural fungal pathogens. Pest Manag. Sci. 71:1054-1058.

Rozen, S., and Skaletsky, H. 2000. Primer3 on the WWW for general users and for biologist programmers. Methods Mol. Biol. 132:365-386.

Schenck, N. C. 1968. Epidemiology of gummy stem blight (Mycosphaerella citrullina) on watermelon: Ascospore incidence and disease development. Phytopathology 58:1420-1422.

Schmitz, H. K., Medeiros, C.-A., Craig, I. R., and Stammler, G. 2014. Sensitivity of Phakopsora pachyrhizi towards quinone-outside-inhibitors and demethylationinhibitors, and corresponding resistance mechanisms. Pest Manag. Sci 70:378-388.

Schnabel, G., and Jones, A. L. 2001. The 14 $\alpha$-demethylase (CYP51A1) gene is overexpressed in Venturia inaequalis strains resistant to myclobutanil. Phytopathology 91:102-110.

Schoonbeek, H., del Sorbo, G., and de Waard, M. A. 2001. The ABC transporter BcatrB affects the sensitivity of Botrytis cinerea to the phytoalexin resveratrol and the fungicide fenpiclonil. Mol. Plant-Microbe Interact. 14:562-571.

Seebold, K. W., and Langston, D. B., Jr. 2003. Evaluation of boscalid for control of gummy stem blight on watermelon, 2003. Fungicide and Nematicide Tests 59: V051.

Simpson, J. T., Wong, K., Jackman, S. D., Schein, J. E., Jones, S. J. M., and Birol, I. 2009. ABySS: A parallel assembler for short read sequence data. Genome Res. 19:1117-1123.

Sitterly, W. R., and Keinath, A. P. 1996. Gummy stem blight. Pages 27-28 in: Compendium of Cucurbit Diseases. T. A. Zitter, D. L. Hopkins, and C. E. Thomas, eds. APS Press, St. Paul, MN.

St. Amand, P. C., and Wehner, T. C. 1995. Eight isolates of Didymella bryoniae from geographically diverse areas exhibit variation in virulence but no isolate by cultivar interaction on Cucumis sativus. Plant Dis. 79:1136-1139.

Stevenson, K. L., Langston, D. B., Jr., and Seebold, K. W. 2004. Resistance to azoxystrobin in the gummy stem blight pathogen documented in Georgia Plant Health Progress Published online. doi:10.1094/PHP-2004-1207-01-RS

Stewart, J. E., Turner, A. N., and Brewer, M. T. 2015. Evolutionary history and variation in host range of three Stagonosporopsis species causing gummy stem blight of cucurbits. Fungal Biol. 119:370-382.

Talas, F., and McDonald, B. A. 2015. Significant variation in sensitivity to a DMI fungicide in field populations of Fusarium graminearum. Plant Pathol. 64:664-670.

Thomas, A., Langston, D. B., Jr., Sanders, H. F., and Stevenson, K. L. 2012a. Relationship between fungicide sensitivity and control of gummy stem blight of watermelon under field conditions. Plant Dis. 96:1780-1784.

Thomas, A., Langston, D. B., Jr., and Stevenson, K. L. 2012b. Baseline sensitivity and cross-resistance to succinate-dehydrogenase-inhibiting and demethylationinhibiting fungicides in Didymella bryoniae. Plant Dis. 96:979-984.

van den Bossche, H., Engelen, M., and Rochette, F. 2003. Antifungal agents of use in animal health - chemical, biochemical and pharmacological aspects. J. Vet. Pharmacol. Ther. 26:5-29.

Wiant, J. S. 1945. Mycosphaerella black rot of cucurbits. J. Agric. Res. 71:193 213.

Yin, Y., Liu, X., Li, B., and Ma, Z. 2009. Characterization of sterol demethylation inhibitor-resistant isolates of Fusarium asiaticum and $F$. graminearum collected from wheat in China. Phytopathology 99:487-497. 